\title{
Lateral Placental Location as a Predictor of Preeclampsia Development: A Prospective Study
}

Mansi J Shah ${ }^{1}$, Sulabha Joshi ${ }^{2}$

\begin{abstract}
Objective: To find whether placental laterality as determined by ultrasound can be used as a predictor of the development of preeclampsia and to find its correlation with severity of preeclampsia and obstetric outcome.

Material and methods: Antenatal care (ANC) patients attending the ANC clinic at 18 to 24 weeks fulfilling inclusion criteria were included. The location of the placenta was determined by ultrasonography at 18 to 24 weeks. The placenta was classified as central when it is equally distributed on the left or right side of the uterus. When $75 \%$ of the placenta is to one side of the midline, it was classified as right or left lateral. All subjects were followed throughout pregnancy for the development of signs and symptoms of preeclampsia which was diagnosed as per ACOG criteria. Results: Among 397 women studied, 53 cases were diagnosed with preeclampsia, while remaining 344 women were normal. Out of 53 cases, 41 (77.3\%) had mild preeclampsia, while12 (22.7\%) had severe preeclampsia. Out of 397 women studied, 205 (51.63\%) women had lateral placenta and $192(48.36 \%)$ women had central placenta. Out of 205 women with lateral placenta, 38 (18.53\%) women developed preeclampsia. Out of 192 women who had central placenta only $15(7.81 \%)$ developed preeclampsia.

Conclusion: Thus the present study concludes that the incidence of preeclampsia is $13.35 \%$. The incidence of lateral placental location is $51.63 \%$. Patients with lateral placenta show a higher incidence of development of preeclampsia that is $71.69 \%$. Women with lateral placental location have 1.77 times greater risk of development of preeclampsia than ones with central placental location.

Clinical significance: This cheap, simple, easy, and feasible investigation could be helpful not only to predict the development of preeclampsia but also to reduce its severity, maternal complications, and neonatal complications associated with it.

Keywords: Placental laterality, Placental location, Predictor, Preeclampsia, Prospective study.

Journal of South Asian Federation of Obstetrics and Gynaecology (2021): 10.5005/jp-journals-10006-1876
\end{abstract}

\section{INTRODUCTION}

One of the commonest medical disorders during pregnancy is preeclampsia, which is a pregnancy-specific hypertensive syndrome.

Over the last few decades, in the developed countries, the occurrence of complications and maternal and perinatal deaths due to preeclampsia have fallen. ${ }^{1}$ This is due to the increasing understanding of the disease process. While in developing countries, the rates of mortality and morbidity remain high. ${ }^{2}$

About 5 to $10 \%$ of pregnancies are complicated by it, and it continues to be a major cause of maternal and perinatal morbidity and mortality. Preeclampsia is the cause for every third case of obstetric morbidity and more than 50,000 maternal deaths a year worldwide. ${ }^{3,4}$

None of the tests for the prediction of preeclampsia is considered as a gold standard. So the search for the ideal predictor is still on. Localization of the placenta by ultrasound at 18 to 24 weeks has also been studied as a predictor of preeclampsia. Lateral placentation is considered as a predictor of preeclampsia in many studies with conflicting results. Ultrasonography is routinely done in the second trimester in all patients. If localization of placenta as central or lateral is done in the same sitting, patients can be followed to test if it is a predictor of preeclampsia. With this aim, this study, placental laterality as a predictor of the development of preeclampsia, was carried out at a tertiary care hospital attached to a medical college.

\section{Materials and Methods}

Study type-Prospective longitudinal

Study place-Tertiary care center attached to a medical college Study period-November 2015 to October 2017
${ }^{1}$ Department of Obstetrics and Gynaecology, NKP Salve Institute of Medical Sciences, Nagpur, Maharashtra, India

${ }^{2}$ Department of Obstetrics and Gynaecology, NKP Salve Institute of Medical Sciences and Research, Lata Mangeshkar Hospital, Nagpur, Maharashtra, India

Corresponding Author: Mansi J Shah, Department of Obstetrics and Gynaecology, NKP Salve Institute of Medical Sciences, Nagpur, Maharashtra, India, e-mail: drmansijshah@yahoo.com

How to cite this article: Shah MJ, Joshi S. Lateral Placental Location as a Predictor of Preeclampsia Development: A Prospective Study. J South Asian Feder Obst Gynae 2021;13(2):87-91.

Source of support: Nil

Conflict of interest: None

\section{Inclusion Criteria}

- Antenatal patients between 18 and 24 weeks of gestation with normal blood pressure in the first trimester

- Singleton pregnancy

- Patients willing for monthly follow-up and delivery at the same hospital.

\section{Exclusion Criteria}

- Women with chronic hypertension

- Multiple pregnancies

- Thyrotoxicosis

- Severe anemia

- Vascular diseases

- Gestational diabetes mellitus

() Jaypee Brothers Medical Publishers. 2021 Open Access This article is distributed under the terms of the Creative Commons Attribution 4.0 International License (https://creativecommons.org/licenses/by-nc/4.0/), which permits unrestricted use, distribution, and non-commercial reproduction in any medium, provided you give appropriate credit to the original author(s) and the source, provide a link to the Creative Commons license, and indicate if changes were made. The Creative Commons Public Domain Dedication waiver (http://creativecommons.org/publicdomain/zero/1.0/) applies to the data made available in this article, unless otherwise stated. 
- Renal diseases

- Epilepsy

- Immunoinflamatory diseases

- Any cardiovascular disorders

- Patients with hemorrhagic disorders or previous thromboembolic episode

- Rh-negative pregnancy

This hospital-based prospective study was carried out in the department of obstetrics and gynecology of a rural, tertiary care hospital attached to a medical college from November 2015 to October 2017 after approval of the Institutional Ethics Committee.

All booked antenatal patients between 18 and 24 weeks of gestation with normal blood pressure in the first trimester attending the antenatal OPD of the investigator and fulfilling the inclusion and exclusion criteria were included in the study after informed written consent.

Women were studied for demographic data. As per case record form, detailed history was obtained and thorough clinical and obstetric examinations were done.

Routine investigations were done-including hemoglobin, blood group, HIV, VDRL, HBsAg, sickling, post glucose blood sugar, urine routine, and microscopy - and the results were noted. Location of the placenta was determined by ultrasound at 18 to 24 weeks in all selected women by expert sonologist of the institute and was noted.

The placenta was classified as central when it was equally distributed on the left or right side of the uterus irrespective of it being anterior, posterior, or fundal. When $75 \%$ of the placenta was to one side of the midline, it was classified as right or left unilateral.

All subjects included in the study were being called at monthly intervals till 28 weeks, after every fortnight till 36 weeks, and weekly till delivery or SOS in case of any danger signs like oliguria, headache, vomiting, blurring of vision, and epigastric pain. During each antenatal visit, thorough clinical and obstetric examinations were done, and patients were considered hypertensive if diastolic blood pressure was greater than or equal to $90 \mathrm{~mm} \mathrm{Hg}$ on two occasions 6 hours apart or single reading of $>110 \mathrm{~mm} \mathrm{Hg}$. Mild preeclampsia was labeled in cases of systolic blood pressure less than $160 \mathrm{~mm} \mathrm{Hg}$ and diastolic blood pressure less than $110 \mathrm{~mm} \mathrm{Hg}$ along with proteinuria. Severe preeclampsia was labeled when systolic blood pressure of $160 \mathrm{~mm} \mathrm{Hg}$ or more and diastolic blood pressure of $110 \mathrm{~mm} \mathrm{Hg}$ or more was noted along with proteinuria.

In the OPD, blood pressure was measured using a sphygmomanometer in a sitting position with her right arm at the level of the heart.

The findings were entered in case record form and statistical analysis was done by appropriate statistical method.

\section{Results}

There were 410 antenatal cases recruited at the outset in this study. During follow-up with gestational time, 13 women could not be tracked and hence were excluded from the study, leaving 397. Among these, 53 cases were diagnosed with preeclampsia, while remaining 344 women were normotensive Table 1.

\section{Discussion}

There were 410 subjects recruited at the outset in the study. During follow-up, 13 subjects could not be tracked and hence were excluded from the study, thus 397 patients were analyzed. Among these 53 (13.35\%) were diagnosed with preeclampsia, while remaining 344 (86.64\%) women were normotensive. The incidence of preeclampsia in the present study was $13.35 \%$.

Placental location was done in all patients included in the study. It was seen that 205 (51.63\%) women had lateral placenta, among which 38 (18.53\%) women developed preeclampsia and 167 (81.46\%) remained normotensive. Also, 192 (48.36\%) women had centrally located placenta, among which 15 (7.8\%) developed preeclampsia and 177 (92.18\%) women remained normotensive. In study by Kakkar, Sandhya, Deepak, and Chandra, the incidence of lateral placental location was similar, $56,68.85,62.74,48.66 \%$, respectively. ${ }^{5-8}$ But in a study by Bhalerao, the incidence is low (26.13\%). ${ }^{9}$

Also, in study by Kakkar, Sadhya, Chandra, and Bhalerao, the incidence of development of preeclampsia in women with lateral placenta was $66.6,66.6,66$, and $73.23 \%$, respectively. These were similar to the present study. However, in a study by Deepak, it was $53.4 \%$ which was lower than the rest.

In this study, out of 53 women who were diagnosed with preeclampsia, 39 (73.58\%) women had mild preeclampsia and $14(26.41 \%)$ had severe preeclampsia. Out of these 14 women, 13 (34.21\%) had the lateral placental location and only 1 (6.66\%) had a central placenta. In a study by Kakkar and Sandhya, the incidence of severe preeclampsia was 16.25 and $11.47 \%$, respectively, which is lower than the present study. While in a study by Deepak this incidence was $5.35 \%$, which is very low as compared to the present study. In a study by Chandra, however, the incidence was found to be $50.98 \%$ which is higher than all studies Table 2 .

It was also observed that high percentage of women with severe preeclampsia had lateral placenta in most studies-100\% in Kakkar and $92.85 \%$ in Sandhya. However, in the present study, only $34.21 \%$ women developing severe preeclampsia had lateral placenta Tables $3 \mathrm{~A}$ and $\mathrm{B}$.

Two patients developed eclampsia, both with lateral placental location. Two patients developed accidental hemorrhage, one of which was normotensive with central placenta and the other was with preeclampsia and with lateral placenta. Thirteen patients had postpartum hemorrhage-10 were from normotensive group, 5 each with the central and lateral placental locations. While the other three were from preeclampsia group, one with central and two with lateral placental location. In a study by Asegaonkar, HELLP syndrome developed in $38.5 \%$, remote from term as compared to $22.9 \%$ patients near term which is very high. ${ }^{10}$ This is because all

Table 1: Distribution of women according to location of placenta

\begin{tabular}{llll}
\hline Placental location & Normotensive (344) & Preeclampsia (53) & Total (397) \\
\hline Central & $177(51.45 \%)$ & $15(28.30 \%)$ & $192(48.36 \%)$ \\
Lateral & $167(48.54 \%)$ & $38(71.69 \%)$ & $205(51.63 \%)$ \\
Chi sq $=9.85, p=0.0008$ & & & \\
\hline
\end{tabular}

Table 1 shows that the lateral placenta is more likely to develop preeclampsia $(p=0.0008)$. It was seen that women with lateral placenta had 1.77 times more chance of development of preeclampsia than ones with the central placenta. 
Table 2: Association of placental location with severity of preeclampsia

\begin{tabular}{llll}
\hline Severity of preeclampsia & Central placenta & Lateral placenta & Total \\
\hline Mild & $14(93.33 \%)$ & $25(65.78 \%)$ & $39(71.58 \%)$ \\
Severe & $1(6.66 \%)$ & $13(34.21 \%)$ & $14(26.41 \%)$ \\
Total & 15 & 38 & 53
\end{tabular}

Fisher exact test, $p=0.047$

Table 2 shows that patients that develop severe preeclampsia are more commonly associated with the lateral placenta $(p=0.047)$.

Table 3A: Distribution of maternal complications in relation to the position of the placenta

\begin{tabular}{|c|c|c|c|c|c|}
\hline \multirow[b]{2}{*}{ Complication } & \multicolumn{2}{|c|}{ Preeclampsia (53) } & \multicolumn{2}{|c|}{ Normotensive (344) } & \multirow[b]{2}{*}{ Total (397) } \\
\hline & Central & Lateral & Central & Lateral & \\
\hline Accidental hemorrage & 0 & $1(2.63 \%)$ & $1(0.56 \%)$ & 0 & 2 \\
\hline Eclampsia & 0 & $2(5.26 \%)$ & 0 & 0 & 2 \\
\hline IUGR & $2(13.33 \%)$ & $2(5.26 \%)$ & $6(3.38 \%)$ & $9(5.38 \%)$ & 19 \\
\hline HELLP & $1(6.66 \%)$ & $2(5.26 \%)$ & 0 & 0 & 3 \\
\hline $\mathrm{PPH}$ & $1(6.66 \%)$ & $2(5.26 \%)$ & $5(2.82 \%)$ & $5(2.99 \%)$ & 13 \\
\hline None & $11(73.33 \%)$ & $29(76.31 \%)$ & $165(93.78 \%)$ & $153(91.61)$ & \\
\hline
\end{tabular}

Table 3B: Distribution of women as per presence of maternal complications in relation to placental location

\begin{tabular}{|c|c|c|c|c|c|}
\hline Placental location & Presence or absence of complications & Preeclampsia & Normotensive & Chi-square value & $p$ value \\
\hline \multirow{2}{*}{ Central + lateral } & Yes & $13(24.52 \%)$ & $26(7.55 \%)$ & 1.93 & 0.00011 \\
\hline & No & $40(75.47 \%)$ & $318(92.44 \%)$ & & \\
\hline \multirow[t]{2}{*}{ Central placenta } & Yes & $4(26.66 \%)$ & 12 (6.77\%) & & 0.05 \\
\hline & No & $11(73.33 \%)$ & 165 (94.35\%) & & \\
\hline \multirow[t]{2}{*}{ Lateral placenta } & Yes & $9(23.68 \%)$ & $14(8.38 \%)$ & & 0.023 \\
\hline & No & $29(76.31 \%)$ & $153(91.61 \%)$ & & \\
\hline
\end{tabular}

Tables $3 \mathrm{~A}$ and $3 \mathrm{~B}$ show that when overall maternal complications in relation to placental location are compared, it was seen that the association of complications with lateral placenta was significant $(p=0.023)$. In patients with central placenta, the association of complications was not found to be significant $(p=0.05)$. Thus it shows that patients with lateral placenta are more prone to have complications.

Table 4: Distribution of APGAR scores of babies delivered to women in this study

\begin{tabular}{|c|c|c|c|c|}
\hline \multirow[b]{3}{*}{ APGAR score } & \multicolumn{4}{|l|}{ Groups } \\
\hline & \multicolumn{2}{|c|}{ Preeclampsia $(n=53)$} & \multicolumn{2}{|c|}{ Normal $(n=344)$} \\
\hline & Central & Lateral & Central & Lateral \\
\hline \multicolumn{5}{|l|}{1 minute } \\
\hline Less than 7 & $2(13.33 \%)$ & $7(18.42 \%)$ & $6(3.38 \%)$ & $7(4.19 \%)$ \\
\hline More than 7 & $13(86.66 \%)$ & $31(81.57 \%)$ & $171(96.1 \%)$ & $160(95.80 \%)$ \\
\hline \multicolumn{5}{|c|}{ Central, Fisher exact, $p=0.24$} \\
\hline \multicolumn{5}{|c|}{ Lateral, Chi sq $=9.85, p=0.001, \mathrm{OR}=5.16$} \\
\hline \multicolumn{5}{|c|}{ PIH vs normal, Chi sq $=1.34, p=0.24$} \\
\hline \multicolumn{5}{|l|}{5 minutes } \\
\hline Less than 7 & 0 & 0 & 0 & 0 \\
\hline More than 7 & 15 & 38 & 177 & 167 \\
\hline
\end{tabular}
at 1 minute. This was found to be significant $(p=0.001)$.

unbooked patients were included in the study and the majority were diagnosed at the first visit whereas in the present study patients were under follow-up. In a study by Saadat, 1 out of 125 eclampsia occurred in $0.6 \%$. 
Table 5: Distribution of babies admitted to NICU in two study groups

\begin{tabular}{|c|c|c|c|c|}
\hline \multirow{2}{*}{ NICU admission } & \multicolumn{2}{|c|}{ Preeclampsia $(n=53)$} & \multicolumn{2}{|c|}{ Normal $(n=344)$} \\
\hline & Central & Lateral & Central & Lateral \\
\hline Yes & $2(13.3 \%)$ & $11(28.94 \%)$ & 17 (9.60\%) & $18(10.77 \%)$ \\
\hline No & $13(86.66 \%)$ & $27(71.05 \%)$ & $160(90.39 \%)$ & $149(89.22 \%)$ \\
\hline \multicolumn{5}{|c|}{ Central, Fisher exact, $p=0.91$} \\
\hline \multicolumn{5}{|c|}{ Lateral, Chi sq $=8.41, p=0.003, \mathrm{OR}=3.372$} \\
\hline \multicolumn{5}{|c|}{ Preeclampsia vs normal, Chi $\mathrm{sq}=154, p=0.21$} \\
\hline
\end{tabular}

Low APGAR scores at 1 minute were seen in babies born to mothers with preeclampsia and with ones having lateral placenta. At 5 minutes all babies had APGAR score of more than 7. No perinatal mortality was seen in this study. Nine (16.98\%) babies of women from the preeclampsia group and 13 (3.77\%) of babies normotensive women had APGAR score less than 7 at 1 minute. Out of these seven (4.19\%) women from both normotensive and seven (18.42\%) women with preeclampsia group had lateral placenta; while six (3.38\%) normotensive women and two (13.33\%) women with preeclampsia had central placenta. In the study by Saadat in 2007, the mean APGAR score in neonates at 1 and 5 minutes of preeclampsia group were 7.6 and 8.8 , respectively, which were lower than for neonates of healthy women which were 0.89 and 9.9 at 1 and 5 minutes, respectively. The association of placental location with APGAR score at 1 minute was not studied by Saadat et al. ${ }^{11}$

In a study by Faizi in 2011, it was found like in our study, lateral placental location is associated with low APGAR scores in babies. However, in a study by Magann, no significant association was found between placental location and low APGAR scores Table 4. ${ }^{12,13}$

Incidence of NICU admission was more for babies of the mother who had preeclampsia and also women with the lateral placenta. It was seen that babies of 13 (24.52\%) women with preeclampsia and $35(10.17 \%)$ normotensive women required NICU admission. Out of this, in the preeclampsia group, 11 (28.84) women had lateral and 2 (13.3\%) had central placenta, while in the normotensive group, 17 (9.60\%) mothers had central and 18 (10.77\%) had lateral placenta Table 5.

\section{Conclusion}

Thus, the present study concludes that the incidence of preeclampsia is $13.35 \%$. When placental location by ultrasound examination is studied in antenatal women between 18 and 24 weeks, the incidence of lateral placental location is $51.63 \%$. Patients with lateral placenta show a higher incidence of development of preeclampsia that is $71.69 \%$. Women with lateral placental location have 1.77 times greater risk of development of preeclampsia than ones with the central placental location. It is also seen that lateral placental location is associated with the development of severe preeclampsia. Also, maternal complications like eclampsia, accidental hemorrhage, HELLP syndrome, and postpartum hemorrhage are more with the lateral placenta. The neonates of mothers with lateral placental location are more prone to have low APGAR scores and more incidence of NICU admission. Hence placental location done at 18 to 24 weeks gestation can be used as a predictor of the development of preeclampsia. If lateral placental location is seen, these women can be closely monitored for early detection of the development of preeclampsia and thus alerting the clinician to review the patients more carefully. This cheap, simple, easy, and feasible investigation could be helpful not only to predict the development of preeclampsia but also reduce its severity, maternal complications, and neonatal complications associated with it.

\section{Consent Form}

\section{Informed Consent Form (ICF)}

Title of research project: Placental Laterality as Predictor of Preeclampsia: A Prospective Study

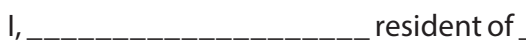

Aged_____years, exercising my free will/choice, without any pressure of incentive in any form, hereby give my consent (as well consent of behalf of patient named

Aged___years as his/her relative) to be included as subject in the

said clinical study.

*strike out matter in bracket if not applicable.

I acknowledge the receipt of - Patient's Information Sheet|| and also the doctors have informed me about this research project suitably and sufficiently to my satisfaction. I agree to let my blood samples be drawn as required. I shall report to the hospital or other place where called on given appointment dates and time. I shall inform the doctors for any adverse effects or unusual symptoms noticed by me. I shall cooperate with the doctors and paramedical staff in all respects. I permit to publish the results of my participation in this study. I shall not be given any reimbursement or compensation. I have been informed of my right to opt out of this research project at any time without giving any reason for doing so.

I hereby record my consent for participation in the said trial.

1.

Patient's name Signature/thumbprint date time

Or the name of the person providing consent signature/ thumbprint date time

2.

Witness name Signature/thumbprint date time

3.

Investigator's name Signature/thumbprint date time 


\section{References}

1. http://www.rcog.org.uk/stratog/page/introduction-pre eclampsia.

2. Cunningham FG, Williams JW. Williams obstetrics. 1866-1931. 23rd ed. New York: McGraw-Hill, Medical; 2010.

3. Duley L. Maternal mortality associated with hypertensive disorders of pregnancy in Africa, Asia, Latin America and Caribbean. Br J Obstet Gynaecol 1992;99(7):547-553. DOI: 10.1111/j.1471-0528.1992.tb13818.x.

4. Duley L. The global impact of pre eclampsia and eclampsia. Semin Perinatol 2009;33(3):130-137. DOI: 10.1053/j.semperi.2009.02.010.

5. Kakkar T, Singh V, Razdan R, et al. Placental laterality as predictor of development of preeclampsia. J Obstet Gynaecol India 2013;63(1):22- 25. DOI: 10.1007/s13224-012-0241-x.

6. Sandhya K, Madhavi GB, Chandramathi M. Placental laterality as predictor of development of preeclampsia. Am J Phytomed Clin Ther 2015;3(3):231-236.

7. Deepak N, Kumari L, Felix AJW. The study of placental laterality and development of preeclampsia. Int J Mod Res Rev 2015;3(9):781-783. ISSN: 2347-8314.
8. Chandra K, Maheshwari S. Placental laterality as a predictor for the development of Preeclampsia. IOSR J Dent Med Sci 2016;15(6):6-10. DOI: 10.9790/0853-1506130610.

9. Bhalerao AV, Kukarni S, Somalwar S. Lateral placentation by ultasonography: a simple predictor of preeclampsia. J South Asian Fed Obstet Gynaecol 2013;5(2):68-71. DOI: 10.5005/ jp-journals-10006-1227.

10. Asegaonkar $P$, Ghike S. Pregnancy outcome in women with pre eclampsia remote from term in a rural tertiary care hospital. PJMS 2014;4(1):40-44.

11. Saadat M, Nejad SM, Habibi G, et al. Maternal and neonatal outcomes in women with preeclampsia. Taiwan J Obstet Gynecol 2007;46(3):255-259. DOI: 10.1016/S1028-4559(08)60029-7.

12. Faizi S, Pai MV. Role of midtrimester localization of placenta in predicting pregnancy outcome. IJIFM 2014;5(3):87-91. DOI: 10.5005/ jpjournals-10016-1087.

13. Magann EF, Doherty DA, Turner K, et al. Second trimester placental location as a predictor of an adverse pregnancy outcome. J Perinatol 2007;27(1):9-14. DOI: 10.1038/sj.jp.7211621. 